\title{
JUURNAL.RU
}

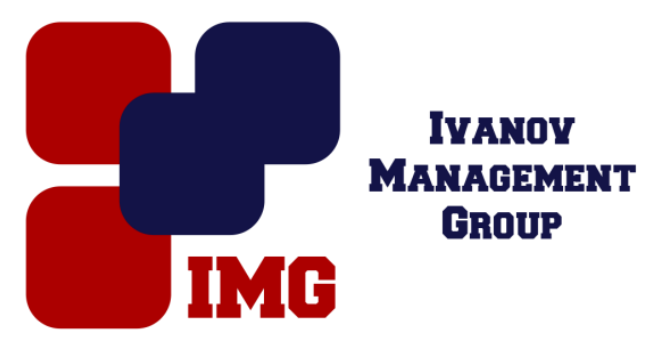

ЧервинскийА.В.

Кубанский Государственный Университет

Краснодар, Россия

doi: $10.18411 / \mathrm{lj}-31-05-2017-64$

idsp 000001:1j-31-05-2017-64

\section{Эффективность взаимодействия субъектов финансового рынка РФ}

\section{Аннотация}

Статья посвящена анализу взаимодействия институтов финансового рынка. Проанализированы и выявлены направления развития субъектов финансового. Определены основные причины слабого взаимодействия субъектов финского рынка.

Ключевые слова: финансовый рынок, институты, особенности, взаимодействие.

Характерной чертой финансовой системы Российской Федерации является значительноепреобладаниекредитных организаций. Данный тезис подтверждается существенным доминированием активов кредитных институтов над активами некраденых финансовых институтов.Так по данным ЦБв 20122015 годах российский финансовый сектор развивался довольно активно (рис 1). За три года значительно выросло отношение активов банковского сектора к размеру ВВП страны с 79,6\% в 2012 году до 102,7\% в 2015 году, а отношениекредитов экономике к размеру ВВП - с 41,6 до 54,4\%,отношение капитала к ВВП- с 9,4 до 11,1\%. 


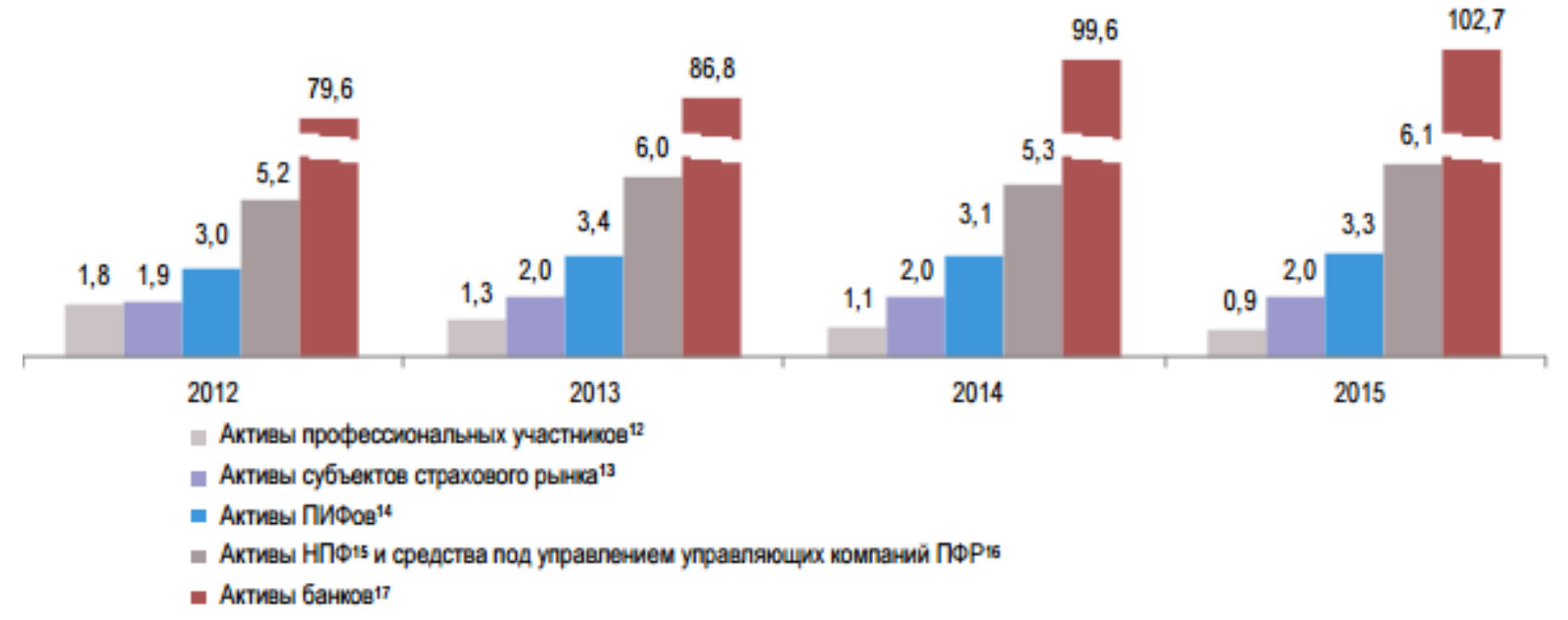

Рисунок. 1. - Динамика активов кредитных организаџий и некоторых некредитных финансовых организаций, \% $B B \Pi$

Что касается активов некредитных финансовых институтов, то наибольший рост показали активы именно пенсионных фондов, доля которых, увеличилась с 5,3\% ВВП в 2012 году до 6,1\% ВВП в 2015 году [4]. Данное явление объясняется изменяем законодательства в пользу поддержки пенсионных фондов

Особенность сложившейся в России финансовой системе заключается в действии ряда факторов: во-первых с довольно низкой активностью населения на финансовом рынке; во-вторых, с изменением предпочтений населения в сторону кредитных организациях, которые стали предоставлять по мимо привычного нам банковского обслуживания, но и различные услуги предоставляемые на фондовом рынке; в-третьих невысоким уровнем доверия к подавляющему большинству некредитных финансовых институтов из-за высокого уровня злоупотреблений в отрасли при недостаточно эффективной надзорной деятельности и отсутствием механизмов воздействия и привлечения к ответственности на недобросовестных участников.

Пожалуй, ключевую роль, не смотря на это, играет довольно высокий спрос банковских вкладов у населения. Поскольку характеристики банковских вкладов сочетают в себе довольно высокие проценты по вкладам, а так же наличием льготного режима налогообложения процентного дохода для вкладов в иностранной валюте. Благодаря системе страхования банковские вклады обладают высоким уровнем надежности, а так же доступностью данного продукта для населения. 
Рынок акций, в значительной степени был сформирован благодаря осуществленной приватизации государственных предприятий, между тем он не смог в полной мере стать полноценным источником для привлечения капитала в силу невысокой эффективности корпоративного управления в большинстве российских открытых акционерных компаний[1].

На отечественном рынке облигаций главенствующую роль занимают заимствования в форме еврооблигаций, номинированные в иностранной валюте, они, главным образом, пользуются спросом со стороны иностранных инвесторов. Многие эксперты давно наблюдают тенденцию, когда иностранные инвесторы занимая деньги в европейских банках под низкие проценты, вкладывают эти деньги в отечественные облигации с более высокой процентной ставкой[3].

На наш взгляд, основным фактором, осуществляющим сдерживание в развитие финансового рынка, является достаточно низкий уровень собственных сбережений населения. Так в общей структуре денежных средств (рис 2), удельный вес использования сбережений остается на довольно низком уровне несмотря на небольшой рост нормы сбережения населения до 14,1\% в 2015 году, за три года его значение составило 10,0\% [4].

Несмотря на достаточно низкую норму сбережений, необходимо подчеркнуть доминирование накоплений домохозяйств, в структуре финансовых продуктов предоставляемых банками. Отношение общего объема вкладов к ВВП в 2015 году составило порядка 28,7\%, что является довольно невысоким значением в сравнении с сопоставимыми развивающимся странам.

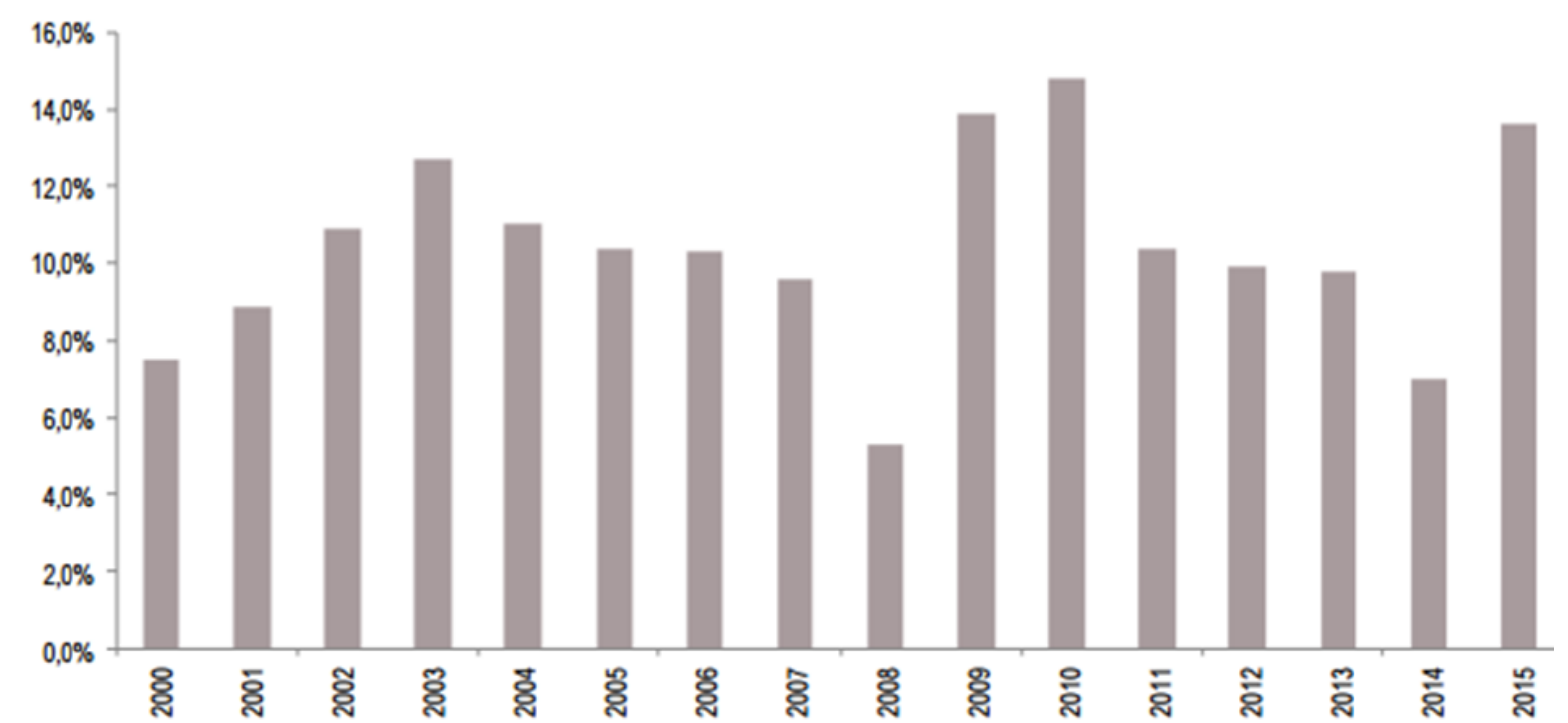

Рисунок 2. - Динамика доли сбережений в структуре использования денежных средств домохозяйств, \% 
Депозиты населения на сегодняшний день являются второй статьей по объему пассивов в кредитных организациях, лишь немного уступая средствам нефинансовых организаций, размещенным на депозитных и расчетных счетах. Между тем напротив, некредитные финансовые продукты, в России пользуются, куда меньшим спросом и их уровень проникновения значительно отстает от, аналогичного в сопоставимых странах с такими же развивающимися рынками. На финансовых ранках большинства стран одними из важнейших инструментов привлечения сбережений домохозяйств, которые также способны служить источником для долгосрочных инвестиций, выступают страховые продукты под различными программами, в том числе страхования жизни.

В России, несмотря на происходящие в последнее годы опережающие темпы роста взносов для страхования жизни, совокупная доля этого сегмента в страховых взносах все еще остается незначительной, составляет $12,7 \%$, когда во многих странах с развитой рыночной экономикой данный показатель превышает 51\%. Соотношение премий по страхованию жизни к ВВП страны в развивающихся странах находиться в диапазоне 1- 15\%, однако в российских реалиях этот показатель приближен к нулю[2].

Интерес инвесторов к таким институтам инвестирования на финансовом рынке, как паевые инвестиционные фондах (ПИФах) и прямые биржевые торги, по-прежнему остается на достаточно низком уровне в сравнении с активностью и эффективностью населения большинства стран с соизмеримым уровнем располагаемого дохода. Тем неимение, стоимость чистых активов интервальных и открытых ПИФов уже долгое время не превышает - 0,2\% от ВВП, данный показатель значительно меньше аналогичного показателя вразвитых и развивающихся стран (рис. 3).

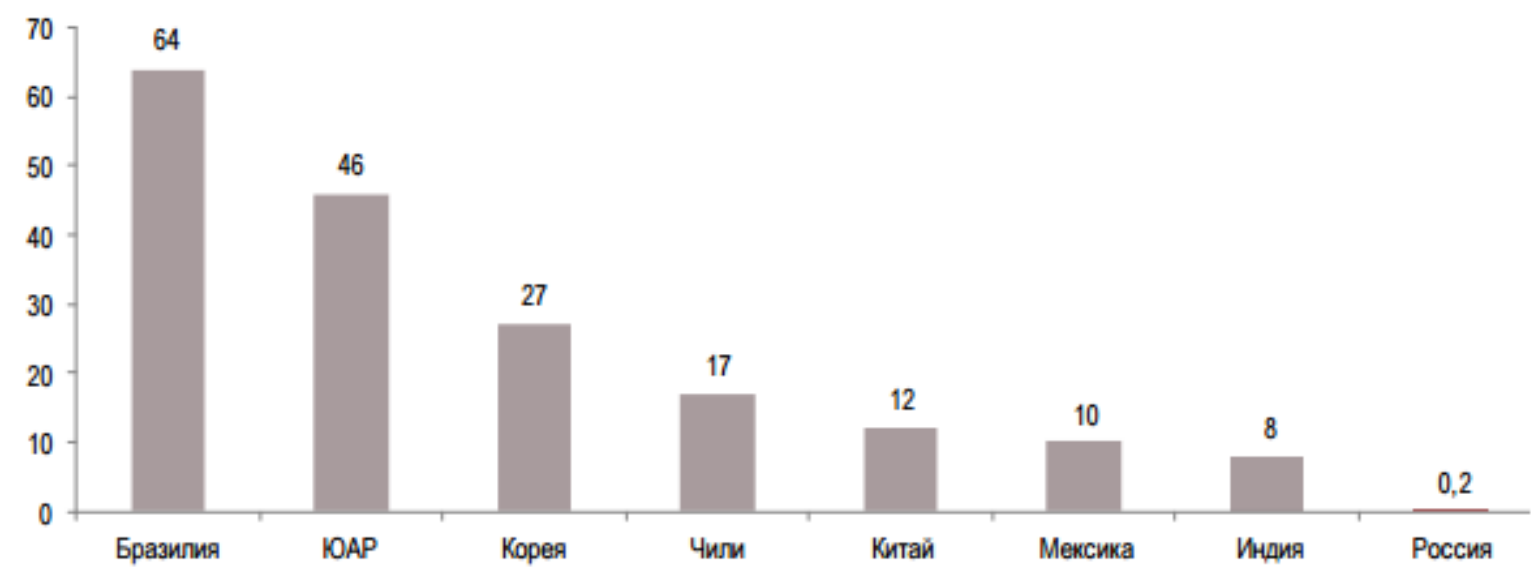

Рисунок 3 - Активы ПИФов в развивающихся странах, \% от ВВП в 2015 году 
Так по данным центрального банка стоимость активов открытых ПИФов, выступающими основным инструментом инвестирования для розничных групп инвесторов, в 2015 году составляла 110,1 млрд рублей. На сегодняшний день доля суммарных активов ПИФов в ВВП страны в 2015 года составила всего $3,3 \%$, разумеется, данное значение находится на недостаточно высоким уровне[4].

Общее количество зарегистрированных физических лиц на фондовом рынке в России, согласно данным ПАО Московская Биржа, в 2015 году достигло 1,3 млн человек, что составляет всего $0,9 \%$ численности населения, или всего $1,7 \%$ от экономически активной части населения (рис. 4).
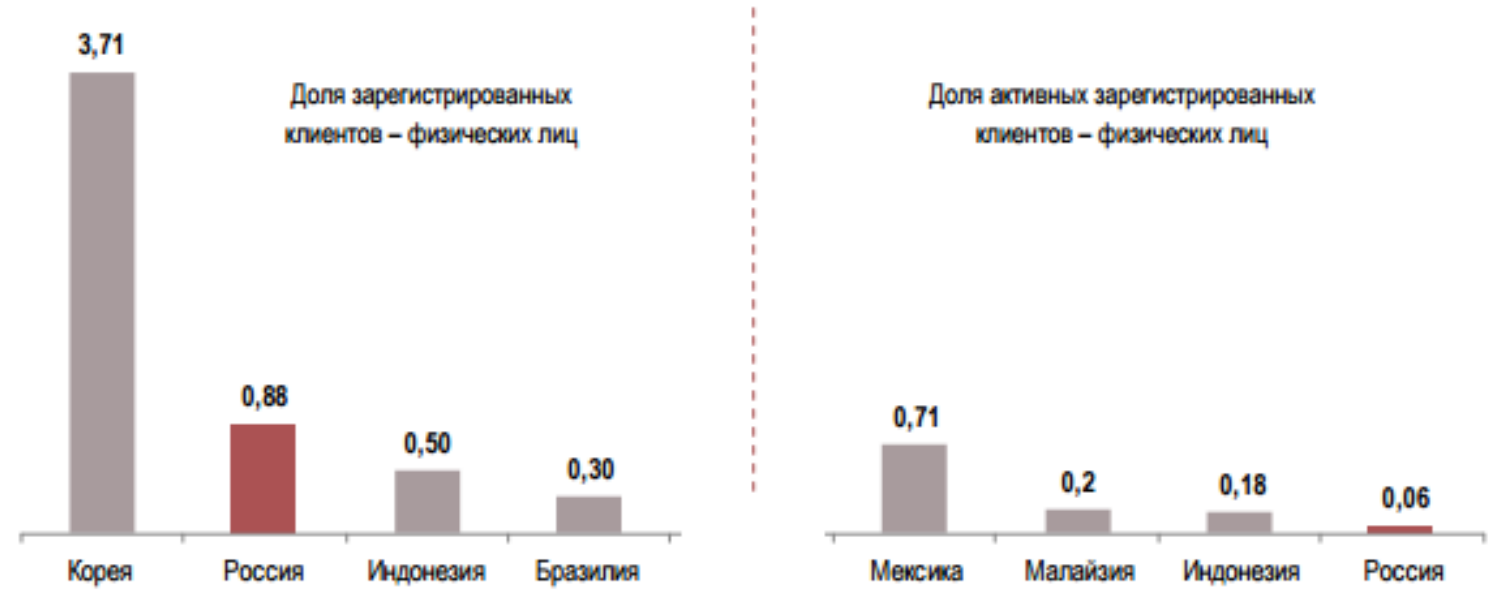

Рисунок 4. - Доля населения, имеющего счета для операџий на фондовом рынке, в отдельных развивающихся странах, \% от общей численности

В качестве возможных мер по вовлечению экономически активной части населения в финансовый рынок следует отметить введённый в январе 2015 года нового финансовый инструмент для привлечения населения - индивидуального инвестиционного счета (ИИС). Он должен снизить налоговую нагрузку, накладываемую на операции физических лиц осуществляющих свою деятельность на финансовом рынке. Кроме того, ИИС является инструментом привлечения физических лиц к инвестированию в национальные компании, акции которых торгуются фондовом рынке нашей страны. Так по состоянию на 2015 год уже было открыто свыше 89,6 тысяч ИИС, их объем торгов составил порядка 43,1 млрд рублей[4].

Складывающиеся тенденции постепенно находят отражение в характере заимствования российских компании, которые теперь вынуждены осуществляя 
финансирование инвестиционных программ, рассчитывая на денежные средства из государственных и муниципальных бюджетов, финансирование за счет контролирующих лиц (рис. 5), свою нераспределенную прибыль, а также на иностранные заимствования, доступ которых в последние годы был значительно снижен.

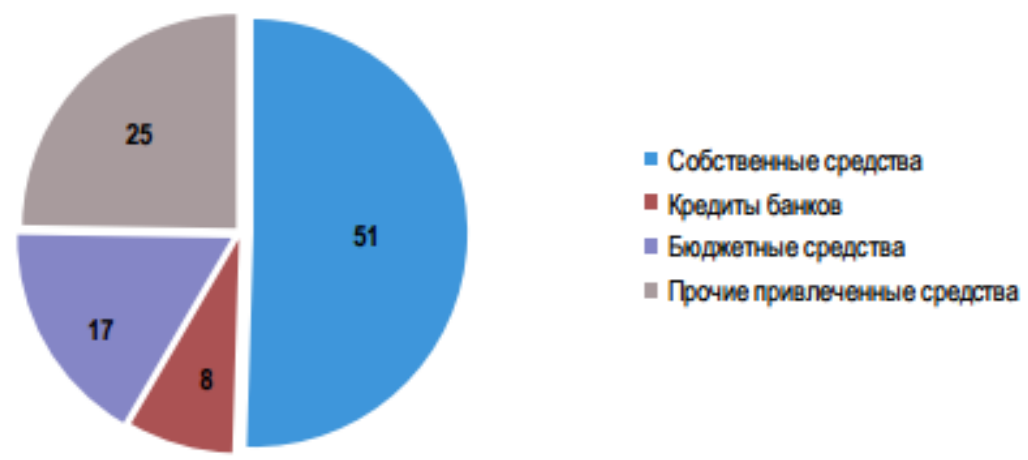

Рисунок 5. - Доля населения, имеющего счета для операџий на фондовом рынке, в отдельных развивающихся странах, \% от общей численности

В сравнении с компаниями в странах с близким уровнем дохода, а также компаниями из стран Центральной Азии и Восточной Европы российские компании значительно меньше используют внешнее источники финансирования, в частности в виде займов у кредитных организаций[1]. Так за счет денежных средств, предоставленных кредитными организаций, в России финансируется все лишь 8\% общих инвестиций в основной капитал. Несмотря на это, российская финансовая система характеризуется преобладанием кредитования как традиционно первостепенного источника заимствования для российских компаний.

Согласно данным центрального банка в 2015 году общий корпоративный кредитный портфель составил 33,3 трлн рублей, что составляет $41,2 \%$ от ВВП. Кредитование реального сектора экономики составляют 54,4\% от ВВП, по этому показателю мы сильно отстаем, от других развивающихся странах[4].

Общий объем публичных заимствований на внешнем рынке корпоративного долга во второй половине 2015 года достиг порядка 128,4 млрд долл.

Общая капитализация всего российского рынка акций в 2015 году составила 28,8 трлн рублей или $35,6 \%$ от ВВП, по данному показателю наша страна находиться значительно ниже общемирового уровня, составляющего $82,3 \%$ от суммарного мирового ВВП. 
Значение коэффициент цена/прибыль акций российского рынка в четыре раза ниже, чем у аналогичного американского, и почти в два раза ниже рынка Китая. Все это объясняется довольно высокими требованиями инвесторов к премии за российские риски в современных геополитических условиях,при низком уровне инвестиционного климата и доверия к корпоративному управлению публичных акционерных компаний.

Для практически всех видов финансовых институтов в России можно наблюдать наблюдается схожую закономерность того, что активы 10-15\% крупнейших компаний, обычно лидеров своего сегмента рынка составляют $80 \%$ всех активов. При этом, несмотря на многочисленность и разнообразие финансовых посредников практически во всех секторах российского финансового рынка, все еще продолжается тенденция к концентрации, так вес первой пятерки крупнейших банков в совокупных активах продолжил рост с 52,7 до 53,6\% в 2014 году, и с 53,6 до 54,1\% в 2015 году.

Аналогичная тенденция наблюдается ив отношении некредитных финансовых институтов, так 39 страховым организациям составляющим 11\% от общего числа не кредитных учреждений принадлежат $80 \%$ совокупных активов. Среди негосударственных пенсионных фондах у 15 учреждений составляющих занимающих 15\% рынка, сконцентрировано $80 \%$ совокупных активов данного сегмента

На 219 ПИФов в2015году или 14\% от их общей численности приходится $80 \%$ совокупных активов ПИФов.

Однако максимальная концентрация находиться у профессиональных участников рынка ценных бумаг, где $80 \%$ всех активов аккумулированы у 7,6\% участников (эту долю составляют 38 компаний)

Одновременно с этим наблюдается тенденция в сторону сокращения количества финансовых посредников. Только, за последние три года численность кредитных организаций сократилась на треть - до 733 кредитных институтов, по состоянию на 2015 год в 2012 их количество составляло 956 организаций. Между тем, количество профессиональных участников рынка ценных бумаг покинувших эту сферу составило 347 или 28,4\%. Количество страховых институтов сократилось - на 124 учреждения $(21,8 \%)$, негосударственных пенсионных фондов - на 32 (26,5\%), а количество ПИФов за тот же период увеличилось на 137 (9\%).

Поводя итого можно сказать, что в нынешних условиях российский финансовый рынок можно охарактеризовать относительно невысокой 
капитализацией рынка акций и достаточно низким соотношением корпоративного долга к уровню ВВП страны. Размещение акций и облигаций в России значительно отстает по объему от банковского кредитования привлекаемых денежных средств. Однако банковский сектор не в состоянии заменить рынок капитала.

1. Глазьев С.Ю. Стратегия опережающего развития России в условиях глобального кризиса М.: Экономика, 2010 г. с.255

2. Дробышевская Л.Н., Исаева Л.А. Развитие синдицированного инвестирования в России: роль краудтехнологий // Экономика устойчивого развития. 2016. № 4 (28). С. 25-32.

3. Дробышевская Л.Н., Конева Т.В. Основные участники и этапы секъюритизации финансовых активов // TerraEconomicus. 2013. Т. 11. № 3-2. С. 17-21.

4. Доклад председателя Центрального банка Э. Набиуллиной о проекте основных направлений единой государственной денежно-кредитной политики на 2015 г. и период 2016-2017 гг. URL: http://government.ru/news/14936. 